\title{
Nitrate leaching from intensive organic farms to groundwater
}

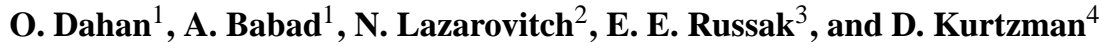 \\ ${ }^{1}$ Department of Environmental Hydrology \& Microbiology, Zuckerberg Institute for Water Research, Blaustein Institutes for \\ Desert Research, Ben-Gurion University of the Negev, Midreshet Ben-Gurion, Israel \\ ${ }^{2}$ Wyler Department of Dryland Agriculture, French Associates Institute for Agriculture and Biotechnology of Drylands, \\ Jacob Blaustein Institutes for Desert Research, Ben-Gurion University of the Negev, Midreshet Ben-Gurion, Israel \\ ${ }^{3}$ Geological and Environmental Sciences, Ben-Gurion University of the Negev, Beer Sheva, Israel \\ ${ }^{4}$ Institute of Soil, Water and Environmental Sciences, Agricultural Research Organization, The Volcani Center, \\ Bet Dagan, Israel
}

Correspondence to: O. Dahan (odahan@bgu.ac.il)

Received: 18 June 2013 - Published in Hydrol. Earth Syst. Sci. Discuss.: 29 July 2013

Revised: 8 December 2013 - Accepted: 11 December 2013 - Published: 27 January 2014

\begin{abstract}
It is commonly presumed that organic agriculture causes only minimal environmental pollution. In this study, we measured the quality of percolating water in the vadose zone, underlying both organic and conventional intensive greenhouses. Our study was conducted in newly established farms where the subsurface underlying the greenhouses has been monitored continuously from their establishment. Surprisingly, intensive organic agriculture relying on solid organic matter, such as composted manure that is implemented in the soil prior to planting as the sole fertilizer, resulted in significant down-leaching of nitrate through the vadose zone to the groundwater. On the other hand, similar intensive agriculture that implemented liquid fertilizer through drip irrigation, as commonly practiced in conventional agriculture, resulted in much lower rates of pollution of the vadose zone and groundwater. It has been shown that accurate fertilization methods that distribute the fertilizers through the irrigation system, according to plant demand, during the growing season dramatically reduce the potential for groundwater contamination from both organic and conventional greenhouses.
\end{abstract}

\section{Introduction}

Developing efficient productive agriculture, while preserving groundwater quality, is one of the most important challenges in water resource sustainability. On the one hand, developing agriculture is straightforward wherever agricultural input, such as water and nutrients, is unlimited. On the other hand, productive agriculture must inherently include the leaching of excess lower quality water below the root zone to the unsaturated zone and ultimately to the groundwater (Shani et al., 2007; Dudley et al., 2008). As such, maintaining the delicate balance between productive agriculture and groundwater quality requires a broad perspective over different time and dimensional scales. While agricultural productivity is measured on a timescale of seasons (several months to several years), its final impact on groundwater is a long-term cumulative process with a timescale of years to decades.

Public awareness of healthy food products that are free of chemical additives, along with a worldwide demand to reduce industrial pollution, has led, in recent years, to the development of organic farming (http//www. organiccenterewales.org.uk/). Although numerous studies have questioned organic agriculture's efficiency (Seufert et al., 2012), sustainability (Trewavas, 2001) and health (Jensen et al., 2012) aspects, organic food markets seem to be thriving in developed countries, as their output is perceived by the public to be healthier for both consumers and the environment. This type of agriculture depends mainly on fertilizers from biological sources, such as composted animal manure. Nevertheless, modern agriculture, whether practiced with conventional or organic methods, needs to reach the goals of mass production, i.e., large quantities and high quality, to satisfy market demand while maintaining economic standards of profitability. This goal is usually achieved through intensive agriculture in greenhouses where irrigation water and fertilizers are implemented in excess to satisfy crop demand 
and maximize productivity. In arid and semi-arid regions, where the climate is warm enough, intensive agriculture in greenhouses operates year round. Moreover, in many of these areas the agriculture is heavily dependent on groundwater resources for irrigation and therefore its quality is of great importance.

Mass production through intensive organic farming is very similar to conventional agriculture in its use of agricultural machinery and modern irrigation techniques; the main differences between the two approaches lie in fertilization and pest-control methodologies (http://www.epa. gov/oecaagct/torg.html; EPA, 2013). Unfortunately, the development of intensive agriculture is often associated with the long-term deterioration of groundwater quality, which is expressed mainly in elevated concentrations of nitrate and salinity (Vitousek et al., 2009; Burow et al., 2010; Kurtzman and Scanlon, 2011; Melo et al., 2012; Morari et al., 2012). Groundwater pollution is usually attributed to a very large array of chemicals. Nevertheless, on a global scale the main cause for drinking-water well shutdowns is a high nitrate concentration in the aquifer water (Osenbruck et al., 2006; Kourakos et al., 2012; Liao et al., 2012; Kurtzman et al., 2013).

The potential for groundwater contamination by nitrate from intensive agriculture is well known (Oren et al., 2004; Vazquez et al., 2006; Thompson et al., 2007). Two main approaches are often used for characterizing nitrate leaching from agricultural fields: (1) characterization of the chemical composition of the soil pore water in shallow depths under the root zone, as may be obtained by application suction lysimeters or sediment samples (Feaga et al., 2010), and (2) determining the cumulative long-term impact on groundwater as may be obtained from the chemical composition of well water (Harter et al., 2002). Apparently, the chemical characteristics of the root zone pore water may vary dramatically in timescales of days to seasons, according to irrigation patterns, fertilizer applications and crop-growing phases. However, the cumulative impact on groundwater develops in timescales of years to decades. The time lag between the initiations of a contamination event near the land surface to its detection in the aquifer water depends on the mechanisms controlling flow and transport in the vadose zone. The ability to characterize flow and transport processes in the vadose zone was recently improved following the development of a vadose zone monitoring system (VMS) that provides realtime, in situ information on the hydraulic and chemical state of the percolating water across the entire vadose zone. Up to now, the VMS has been implemented in a variety of hydrological setups, including (1) flood water percolation (Dahan et al., 2007, 2008; Amiaz et al., 2011), (2) rain water percolation through thick unsaturated sand and clay formations (Rimon et al., 2007, 2011b; Baram et al., 2012a), and (3) solute transport in the vadose zone (Dahan et al., 2009; Rimon et al., 2011a; Baram et al., 2012b).
A newly established agricultural area that has recently been modified from non-intensive open field agriculture to intensive organic and conventional agriculture in greenhouses provided a unique opportunity to investigate the contamination potential of these two agricultural regimes. As such, the main objective of the study was to compare the groundwater pollution potential of organic versus conventional greenhouses as it is expressed through the downleaching of nitrate through the vadose zone underlying these farms. The study was conducted using VMSs that allowed in situ monitoring of the unsaturated zone under selected organic and conventional greenhouses.

\section{Method}

\subsection{Study area}

The study area consists of 100 ha of new greenhouses that were constructed during 2008-2009 on land that had previously been cultivated for $\sim 6$ decades under a non-intensive growing regime (mostly rain-fed open field crops). The site is located on the Mediterranean coastal plain, south of the city of Ashkelon, Israel ( 3-6 km from the sea shoreline). Most of the greenhouses in this area produce high-quality vegetables year round through organic methods $(80 \%)$, while the rest practice conventional methods.

Underneath these agricultural fields $(\sim 15-30 \mathrm{~m}$ below the surface) lies a phreatic sandy aquifer that is characterized by high water quality $\left(\mathrm{Cl}^{-}<200 \mathrm{mg} \mathrm{L}^{-1} ; \mathrm{NO}_{3}^{-}<40 \mathrm{mg} \mathrm{L}^{-1}\right)$. This part of the aquifer is an important water source for the region. Its water is used for domestic and agricultural purposes through a large number of pumping wells. In addition, the aquifer in the region serves as an underground storage area through the artificial infiltration of flood water from the Shikma ephemeral stream and the water surplus from the national water carrier.

The climate in the area is Mediterranean with an annual average precipitation of $458 \mathrm{~mm}$ (Israeli Water Authority, 2013). The majority of the rain events take place during the winter, between December and February. The annual average temperature is $20.2^{\circ} \mathrm{C}$. The coldest month is January with average maximum and minimum temperatures of $17.2^{\circ} \mathrm{C}$ and $8.1^{\circ} \mathrm{C}$, respectively. The warmest month is August with average maximum and minimum temperatures of 31.1 and $21.4^{\circ} \mathrm{C}$, respectively (Israel Meteorological Service, 2013). The pan evaporation rate changes from an average of $2.2 \mathrm{~mm}$ per day in January to $7.5 \mathrm{~mm}$ per day in July (Israel Meteorological Service, 2013). Note that the studied sites are all located inside large greenhouses $(\sim 1$ ha each) that are not influenced by the rain pattern, and their interior climate is warmer and more humid than external natural conditions. Most of the cultivated areas are located in large interdune valleys, surrounded by sandy dunes with sparse vegetation. The stratigraphic cross section of both sites is characterized 
Table 1. Vertical distribution of monitoring units across the vadose zone of the organic and conventional farms.

\begin{tabular}{|c|c|c|c|c|c|c|c|c|c|c|c|}
\hline \multirow{2}{*}{$\begin{array}{l}\text { Farm } \\
\text { Organic }\end{array}$} & \multirow{2}{*}{$\begin{array}{l}\text { Probe } \\
\text { FTDR }\end{array}$} & \multicolumn{9}{|c|}{ Depth to monitoring unit center $(\mathrm{m})$} & \multirow{2}{*}{$\begin{array}{c}\begin{array}{c}\text { Depth to } \\
\text { water table } \\
(\mathrm{m})\end{array} \\
15\end{array}$} \\
\hline & & 0.2 & 0.4 & 0.9 & 1.9 & 2.9 & 4.9 & 7.8 & 10 & 12.8 & \\
\hline & VSP & 0.2 & 0.4 & 1.3 & 2.3 & 3.3 & 5.3 & 8.3 & 10.5 & 13.3 & \multirow{3}{*}{26} \\
\hline \multirow[t]{2}{*}{ Conventional } & FTDR & 0.2 & 0.4 & 0.7 & 1.7 & 2.7 & 5.7 & 9.6 & 14.6 & 19.6 & \\
\hline & VSP & 0.2 & 0.4 & 1 & 2 & 3 & 6 & 10 & 15 & 20 & \\
\hline
\end{tabular}

by interchanges of sandy clay loam to clay loam layers. Yet the vadose zone under the organic farm includes more presence of clay loam layers.

\subsection{Monitoring setup}

Two representative greenhouses, organic and conventional, that specialize in growing vegetables, such as cherry tomatoes, peppers and zucchini, were selected and instrumented with VMSs (Fig. 1). Technical descriptions of VMS structure, performance and installation procedures have been previously presented in other publications (Rimon et al., 2007; Dahan et al., 2008, 2009; Rimon et al., 2011a). To avoid overloading this manuscript with technical information, only a brief description will be presented here. The VMS is composed of a flexible sleeve installed in uncased slanted $\left(35^{\circ}\right)$ boreholes hosting multiple monitoring units at various depths. Each monitoring unit has a flexible time domain reflectometry sensor (FTDR), for continuous measurements of sediment water content, and vadose zone sampling ports (VSP) for frequent collection of pore-water samples from the entire unsaturated zone. Slanted installation ensures that each monitoring unit faces an undisturbed sediment column that extends from land surface to the probe depth. In the borehole, the flexible sleeve is filled with high-density solidifying material to ensure sleeve expansion for proper attachment of the monitoring units to the borehole's irregular walls, sealing its entire void and preventing potential crosscontamination by preferential flow along the borehole. Each VMS included nine monitoring units distributed vertically and laterally along the entire vadose zone cross section (Table 1). Installation orientation was aligned with the growing rows. The representativeness of measurements made by the VMS, with respect to vadose zone sedimentological heterogeneity, has already been discussed in previous publications (Dahan et al., 2007; Rimon et al., 2007).

The VMS provided continuous information from 18 fixed points from the vadose zone underlying the two selected sites throughout a sampling period of 18 months. Each monitoring unit provided high-resolution information from multiple points that are located away from each other vertically and horizontally. Therefore the integrated data from the VMS should be regarded as representative of a wider zone rather

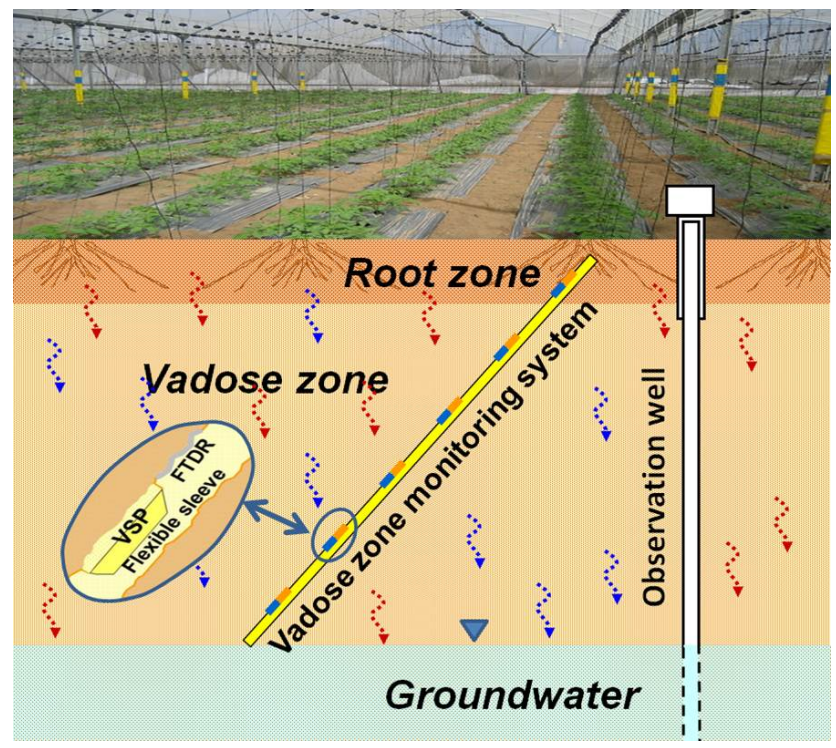

Fig. 1. Schematic illustration of a Vadose zone Monitoring System (VMS) installed under the studied greenhouse. The VMS includes a flexible sleeve hosting multiple monitoring units. The monitoring units are composed of water content sensors (FTDR) and pore water sampling ports (VSP) that are distributed across the entire vadose zone from land surface to groundwater.

than a vertical profile (Fig. 1). To overcome potential bias due to local heterogeneity, the VMS results were compared with the chemical composition of sediment samples that were obtained from additional locations in each greenhouse, and from additional greenhouses owned and cultivated by different farmers. In addition to the VMS that monitored the vadose zone, each site was instrumented with an observation well that penetrated the upper phreatic groundwater with screens to $5 \mathrm{~m}$ below the water table (Fig. 1). In order to validate the results obtained by the VMS, nitrate profiles in the vadose zone pore water were compared with the nitrate concentrations in sediment samples from three additional boreholes in each greenhouse. Samples were collected at a $0.5 \mathrm{~m}$ depth resolution from the top $3 \mathrm{~m}$ of the profile using a standard hand auger. 


\subsection{Chemical and isotopic analysis}

Nitrate concentrations in the water samples were determined using ion chromatography (DIONEX, 4500I). Soil samples were extracted by KCL and analyzed for ammonium by the Nesslerization method (APHA, 1989), for nitrite using the colorimetric method, and for nitrate using the secondderivative method (APHA, 2005). Total nitrogen in the soil was analyzed following the Kjeldahl method (Benton, 1999). The isotopic composition of $\delta^{15} \mathrm{~N}$ and $\delta^{18} \mathrm{O}$ of nitrate in the water samples was determined through nitrate reduction to nitrogen dioxide, which was then analyzed using a gas mass spectrometer (McIlvin and Altabet, 2005).

Throughout the study, the following data were collected: (1) crop type and growing cycle, (2) irrigation quantity and quality, (3) fertilization regime, (4) temporal variation of the vadose zone water-content profile, (5) chemical composition of the vadose zone and underlying groundwater, and (5) isotopic composition $\left(\delta^{15} \mathrm{~N}-\delta^{18} \mathrm{O}\right)$ of nitrate obtained from the vadose zone pore water.

\section{Results and discussion}

\subsection{Agrotechnical regime}

A comparison of agrotechnical regimes implemented in the organic and conventional greenhouses showed very similar general inputs. For example, during a single growing season for cherry tomato, which extended for 183 and 190 days in the organic and conventional greenhouses, respectively, the total irrigation amounts (applied through drip irrigation) were 3440 and $3570 \mathrm{~m}^{3} \mathrm{ha}^{-1}$, respectively (Fig. 2). Throughout the growing season, irrigation in the conventional farm gradually increased with the plant growing phase until the middle of the season, while on the organic farm irrigation is kept relatively constant throughout the entire season. In both greenhouses, the growing season began with an establishment irrigation of $200-240 \mathrm{~m}^{3} \mathrm{ha}^{-1}$. In general, establishment irrigation is implemented to prepare the upper soil for the new planting and down-leaching of salts such as sodium chloride that have accumulated in the root zone during the previous season (Yin et al., 2007; Ben-Gal et al., 2008). In addition, in the organic regime, the establishment irrigation enhances the mineralization of nutrients from the compost in the soil for plant uptake.

Total $\mathrm{N}$-fertilizer implementation in both greenhouses from their establishment date $(\sim 4 \mathrm{yr})$ was very similar, 3800 and $3700 \mathrm{~kg} \mathrm{Nha}^{-1}$ for the organic and conventional greenhouses, respectively. In the organic greenhouse, $98 \%$ of the $\mathrm{N}$ was applied as compost (processed from dairy farms and poultry manure) that was mixed with the soil between the growing seasons, and guano (seabird excrement) that was embedded in the top soil by the plant stems during the growing season. In the conventional greenhouse, on the other

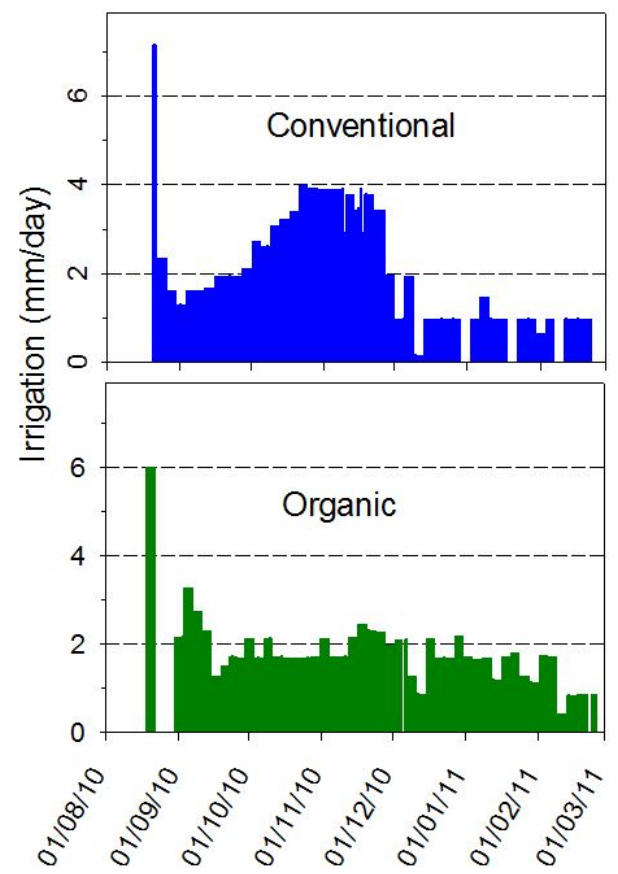

Fig. 2. Daily irrigation during a single growing season of tomato in the organic and conventional greenhouses.

hand, only $45 \%$ of the $\mathrm{N}$ was applied as compost, mainly as a soil amendment in the early stages after the establishment of the greenhouse, while the rest was provided through the drip irrigation system, as mineral liquid fertilizer from industrial sources.

\subsection{Nitrate leaching in the vadose zone}

Water samples from the vadose zone and groundwater were collected at both sites every 3 to 6 weeks for 19 months (total of 262 water samples). A comparison of nitrate concentrations in the vadose zone pore water at the two sites throughout all sampling campaigns exhibited a striking difference (Fig. 3). Nitrate concentrations below the root zone ( $>1 \mathrm{~m})$ under the organic greenhouse exhibited a very high average concentration of $357 \mathrm{mg} \mathrm{L}^{-1}$, with a peak average concentration of $724 \mathrm{mg} \mathrm{L}^{-1}$ at a depth of $2.5 \mathrm{~m}$. Nitrate concentrations below the root zone of the conventional greenhouse were much lower, with an average value of only $37.5 \mathrm{~m} \mathrm{~L}^{-1}$. A closer look at the upper part of the unsaturated zone of both sites exhibited an opposite concentration pattern. Nitrate concentrations under the conventional greenhouse showed a high average concentration of $270 \mathrm{mg} \mathrm{L}^{-1}$ in the root zone $(<1 \mathrm{~m})$ that quickly reduced in the deeper part of the vadose zone. This pattern is preferable for both agronomic and environmental reasons as nitrogen is available for root uptake in the shallow zone with minimal down migration of nitrate to the deeper parts of the vadose zone. On the other hand, under the organic greenhouse, the root zone suffered from a relative shortage of nitrate with an average concentration of 


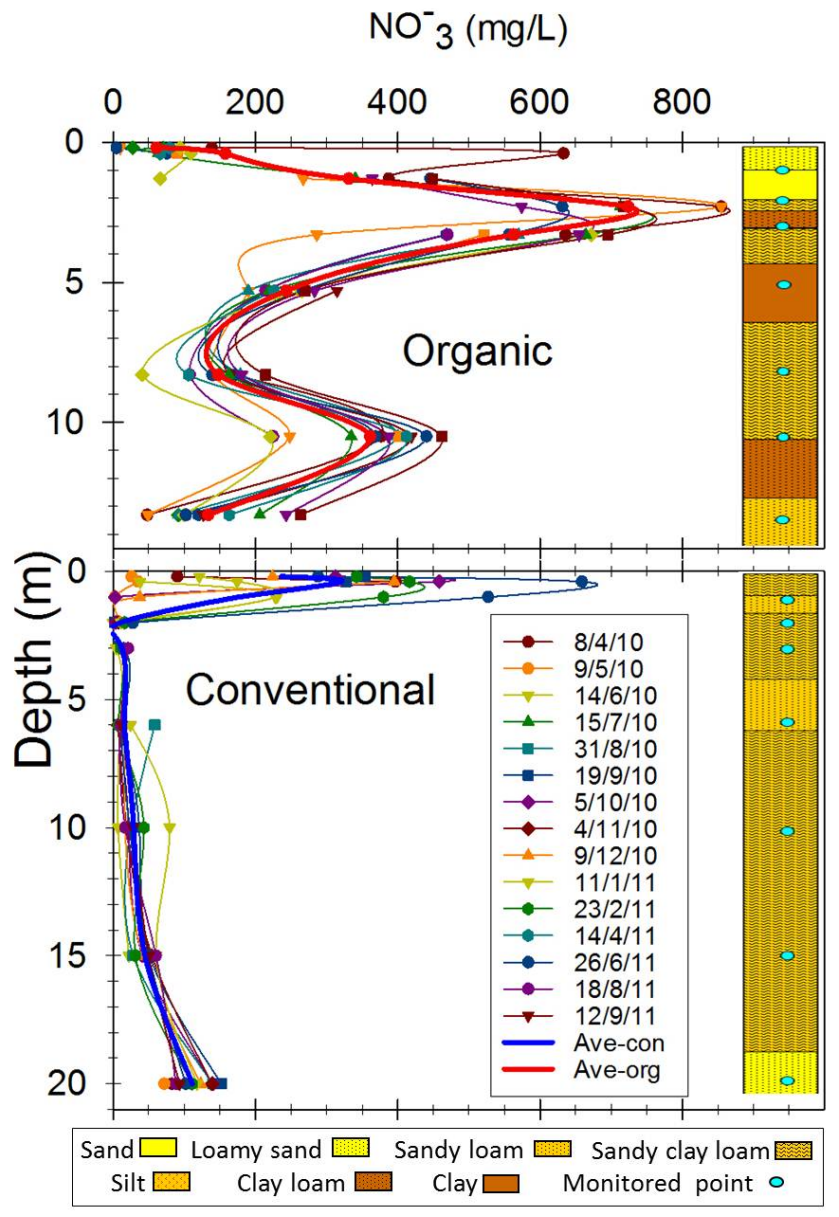

Fig. 3. Nitrate concentrations in the water samples collected by the VMS from the vadose zone underlying the organic and conventional greenhouses along with the lithological cross section of each site. Nitrate profiles were established through 15 sampling campaigns over an 18 month period.

only $109 \mathrm{mg} \mathrm{L}^{-1}$, while a significant increase in the concentration was observed in the deeper parts of the vadose zone, where it is out of reach for plant uptake and poses a threat to groundwater quality. This nitrate concentration pattern is obviously not desirable for either agronomic or environmental reasons. Note that the drinking water standard in most developed countries dictates nitrate concentrations to be lower than $50 \mathrm{mg} \mathrm{L}^{-1}$.

\subsection{Identification of nitrate sources in the vadose zone}

Nitrate concentration profiles in the vadose zone under the two greenhouses indicated significant differences. While investigating the reasons for these differences, one should bear in mind that the two greenhouses differ mainly in fertilization method. Both were established in the same period in the same area on land that was previously used for nonintensive agriculture; both grow similar vegetables, apply

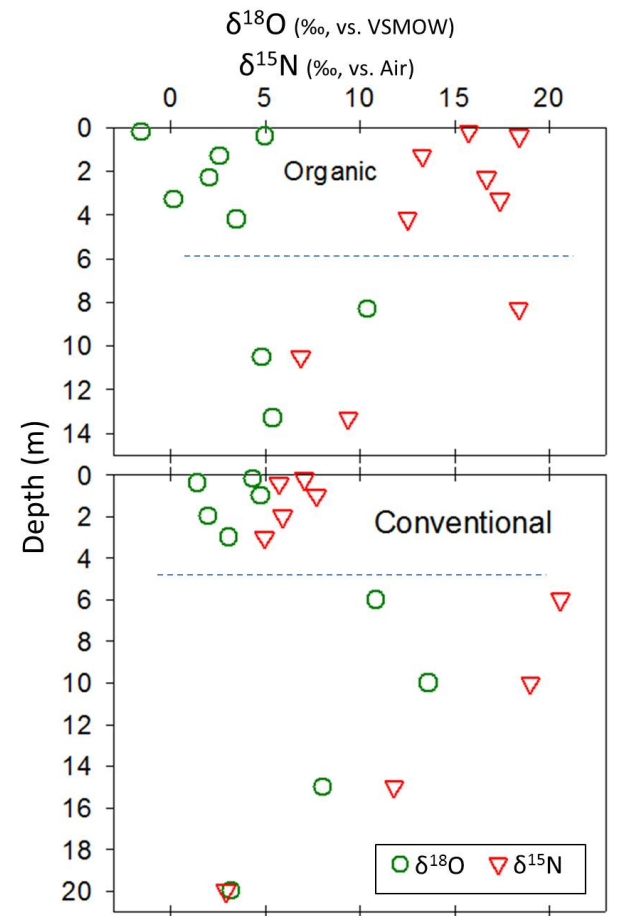

Fig. 4. $\delta^{18} \mathrm{O}$ and $\delta^{15} \mathrm{~N}$ profiles of nitrate in the water samples obtained from the vadose zone underlying the organic and conventional greenhouses (VSMOW refers to Vienna Standard Mean Ocean Water).

a similar amount of $\mathrm{N}$-fertilizers and use a similar amount of water. Nevertheless, the nitrate concentration profiles appear to be very different (Fig. 3). Identification of the nitrate sources in the vadose zone might be examined through the isotopic composition of $\delta^{15} \mathrm{~N}$ and $\delta^{18} \mathrm{O}$ in the nitrate molecules. An isotopic analysis of nitrate in the water samples from the vadose zone exhibited significant differences in isotopic composition in the upper $\sim 5 \mathrm{~m}$ of each site (Fig. 4 ). $\delta^{15} \mathrm{~N}$ values in the upper part of the vadose zone underlying the organic greenhouse are rather heavier (average $\delta^{15} \mathrm{~N}=15.6 \%$; $\mathrm{STD}=2.12$ ) in comparison with the depleted $\delta^{15} \mathrm{~N}$ values observed under the conventional greenhouse (average $\delta^{15} \mathrm{~N}=6.26 \%$; $\mathrm{STD}=0.98$ ). The differences in isotopic composition in the upper part of the vadose zone correspond well with the expected isotopic values of processed manure versus synthetic fertilizer and natural soil nitrogen (Fig. 5) (Kendall and McDonnell, 1999).

One direct implication of the isotopic composition is the accurate identification of the penetration depth of the agricultural leachates. Though the nitrate concentration profiles are very different (Fig. 3), the isotopic fingerprint shows that after four years cultivation in the new established greenhouses agricultural leachates penetrated to a depth of $\sim 5-7 \mathrm{~m}$ in both greenhouses (Fig. 4). Although the impacted depth in both greenhouses is similar, the concentration pattern beneath the root zone in the conventional greenhouse shows 


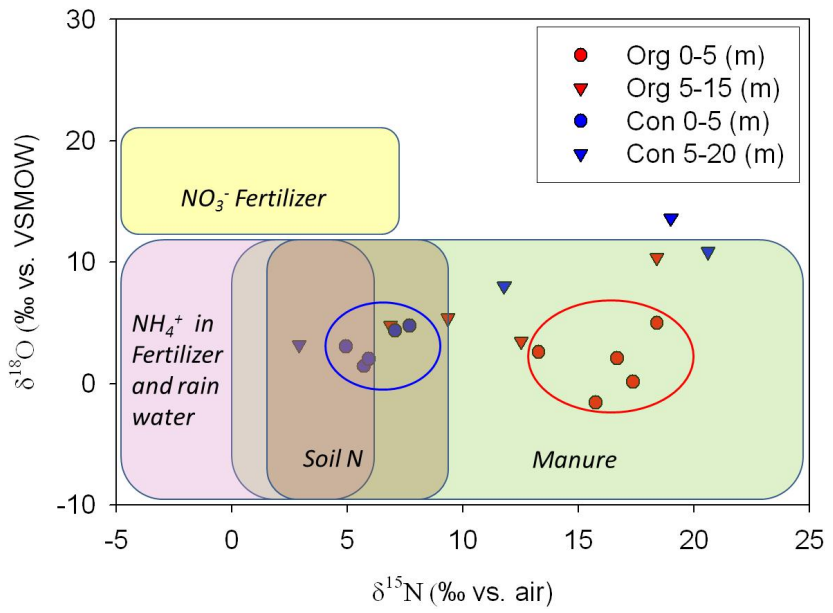

Fig. 5. Isotopic composition of $\delta^{15} \mathrm{~N}$ vs. $\delta^{18} \mathrm{O}$ of nitrate in the water samples from the vadose zone underlying organic (Org) and conventional (Con) greenhouses with respect to typical values in common $\mathrm{N}$ sources (VSMOW refers to Vienna Standard Mean Ocean Water).

significantly lower concentrations as compared with those of the organic greenhouse.

\subsection{Results validation}

To validate the representativeness of the results that were obtained by the VMS a sediment sampling campaign that included three boreholes to the upper vadose zone was carried in each greenhouse. Note that while the VMS collects the sediment mobile pore water, the sediment sample extract provides the entire solute capacity of the sediment, which includes both the mobile and immobile phases (Rimon et al., 2011a). Comparing nitrate concentrations that were obtained by the VMS with those obtained from the sediment extract shows that nitrate concentrations in sediment samples from the upper part of the vadose zone under the organic greenhouse gradually increase from an average value of $8.8 \mathrm{mg} \mathrm{kg}^{-1}$ in the root zone to $85.8 \mathrm{mg} \mathrm{kg}^{-1}$ at a depth of $3 \mathrm{~m}$ (Fig. 6). However, nitrate concentrations in sediment samples obtained from the conventional greenhouse were significantly lower, with an average value of $14.7 \mathrm{mg} \mathrm{kg}^{-1}$ over the entire measured profile. The difference between the mean nitrate concentration under the conventional and organic farms at depths of 1 to $3 \mathrm{~m}$ was found to be significant $(P=0.03$ for a two-tail $t$ test). Apparently, the nitrate concentration pattern that was obtained through the sediment samples is very similar to the nitrate concentration pattern that was observed by the VMS. For convenience of comparison, nitrate concentration in water samples that were obtained by the VMS (Fig. 3) were converted in Fig. 6 from concentrations in pore water to concentrations in dry soil.

To extend representativeness of the findings, the survey was extended to six greenhouses, three organic and three conventional. All six greenhouses were established at the same

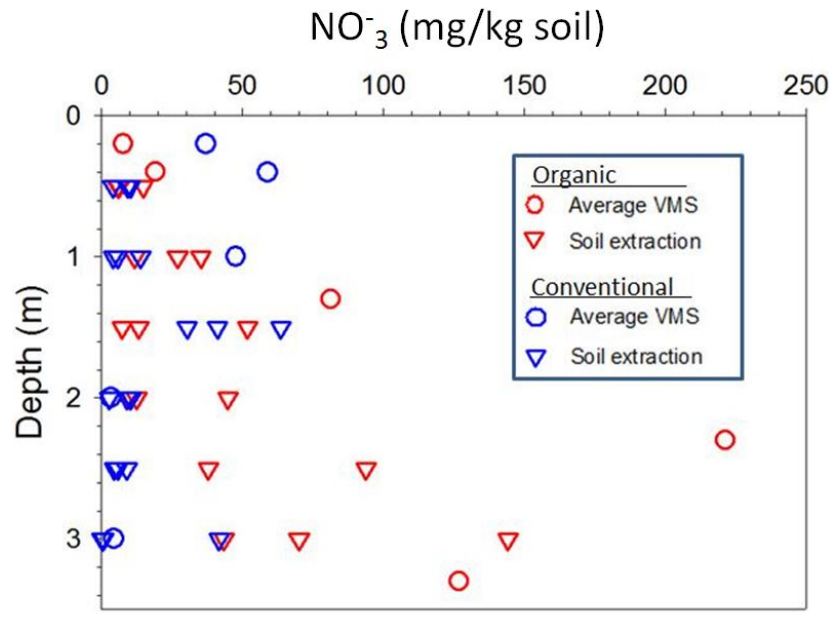

Fig. 6. Nitrate concentrations in sediment samples (soil extraction) and pore water (average VMS) in the vadose zone underlying organic and conventional greenhouses.

time, in the same area (within a distance of up to $5 \mathrm{~km}$ from each other). To avoid potential bias due to farmers' specific working methods, the extended survey included farms that were all owned and operated by different farmers. The top $3 \mathrm{~m}$ of the sediment in each greenhouse was sampled in two boreholes with a depth sampling resolution of $0.5 \mathrm{~m}$ (total of 72 sediment samples). The nitrate concentrations in the sediment samples from the extended survey showed ambiguous results (Fig. 7). Two organic greenhouses exhibited nitrate concentrations that increased with depth, from $27.1 \mathrm{mg} \mathrm{kg}^{-1}$ at $0.5 \mathrm{~m}$ to $133 \mathrm{mg} \mathrm{kg}^{-1}$ at $3 \mathrm{~m}$. On the other hand, the nitrate concentration patterns under all the conventional greenhouses exhibited lower average concentrations, ranging between 34.2 to $44.1 \mathrm{mg} \mathrm{kg}^{-1}$. This difference in nitrate profile is very similar to the pattern that was observed by the VMS over a long period of continuous monitoring (Fig. 2). Nevertheless, nitrate concentration profiles under one of the organic greenhouses exhibited a rather low concentration profile with an average value of $29.9 \mathrm{mg} \mathrm{kg}^{-1}$ (ranging between 27.4 to $32.9 \mathrm{mg} \mathrm{kg}^{-1}$ ). These results, however, did not match the results obtained from the other organic greenhouses. A closer examination of the fertilization methods practiced by the farmers showed that in the two greenhouses where nitrate concentrations increased with depth, the $\mathrm{N}$-fertilizer source had been solid organic matter (compost and guano) mixed into the soil, a method that is commonly practiced in organic farming. On the other hand, in the organic greenhouse that exhibited low nitrate concentrations, $\mathrm{N}$-fertilization relied mainly on the water extracts of guano excrement that had been applied directly through the drip irrigation throughout the growing season, and not as solid compost mixed with the soil prior to the growing season. Fertilization with the irrigation water (fertigation) throughout the growing season in 


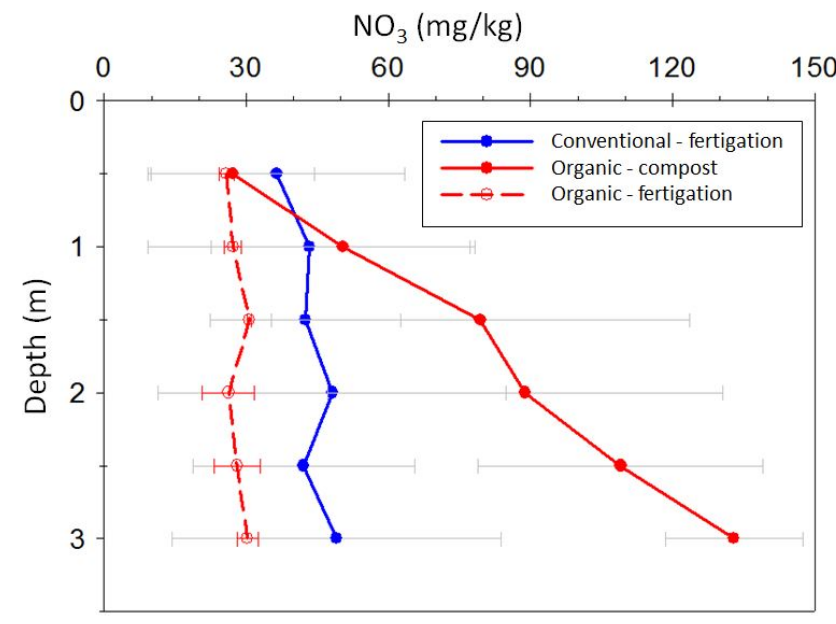

Fig. 7. Average nitrate concentration in sediment samples obtained from the upper part of the vadose zone underlying: (1) organic greenhouses that implement compost as the sole fertilizer, (2) conventional greenhouses that rely on fertigation, and (3) organic greenhouses that use fertigation rather than solid compost.

response to the plant nutrient demand is a common practice in conventional agriculture.

\subsection{Fertilization method and nitrate leaching}

Reexamination of the nitrate concentration profiles in the vadose zone under the greenhouses suggests categorizing the potential down-leaching of nitrate according to the fertilization method rather than the general agro-technical regime of organic versus conventional agriculture. As such the differences in nitrate profiles may be attributed to solid versus liquid fertilizer application. Solid fertilization refers to the application of organic matter such as compost directly to the soil, primarily before planting, as commonly practiced in organic agriculture. On the other hand, liquid fertilization refers to application of fertilizers via the irrigation system throughout the growing season (fertigation), as is commonly practiced in conventional agriculture. Under these two categories, the differences in nitrate concentrations in deep sections $(>1 \mathrm{~m})$ of the vadose zone were much more significant $(P=0.0002)$, showing a tremendous increase in nitrate concentration with depth in farms relying on solid fertilizer application (Fig. 8). Examination of the total nitrogen (TN) amount that was observed in the sediment samples from the upper section of the vadose zone under all of the greenhouses, organic and conventional, showed very similar values. Note that among the main nitrogen forms in the soil (nitrate, ammonium and organic-N), nitrate is much more mobile compared with other forms. Moreover, under aerobic conditions, which typically prevail in the vadose zone of semi-arid regions, nitrate is considered stable, and therefore, its transport across the vadose zone to groundwater persists. Ammonium and nitrite concentration in pore-water samples

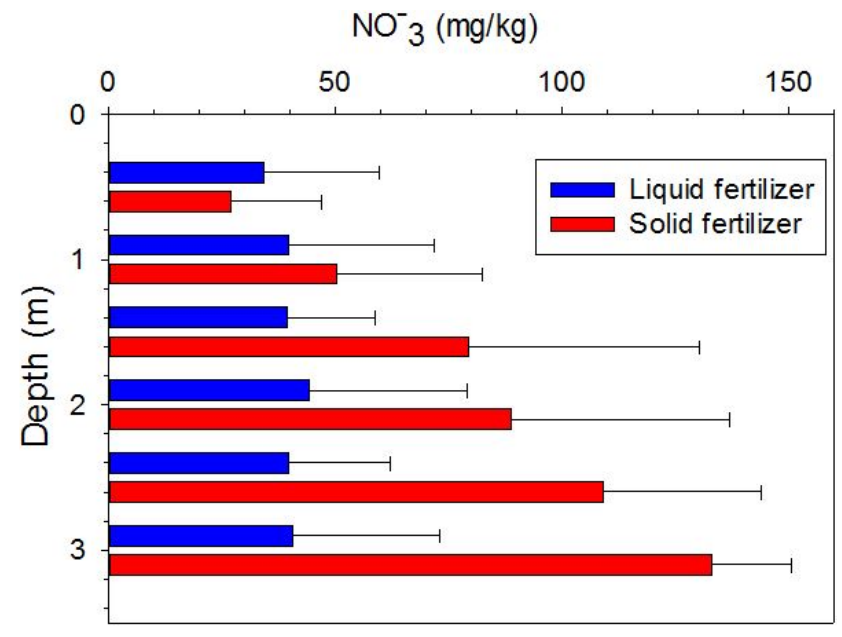

Fig. 8. Nitrate concentrations in the vadose zone underlying greenhouses fertilized by solid fertilizers as compost and guano and liquid fertilizers.

were either negligible or below detection limit and therefore not discussed here.

The observations of enhanced down-leaching of nitrate under intensive farms that rely on solid fertilizers may be attributed to unsynchronized nutrient release from the compost to the soil with respect to the nutrient uptake capacity of the plants. During the early stages of the growing season, an excess of irrigation water, with respect to the plant water and the nutrient uptake, creates a nutrient surplus in the soil (Pang and Letey, 2000). At this stage, the soil water content remains high as does the nutrient concentration, which is released from the compost to the wet soil. However, in the early stages of the growing season water and nutrient consumption by the undeveloped roots of the young plants is limited. Therefore down-leaching of water enriched with nitrate to the deeper parts of the vadose zone is unavoidable. On the other hand, accurate fertigation methods that synchronize the fertilizer's implementation with the nutrient uptake capacity of the plants, as is commonly practiced in conventional agriculture, dramatically reduce the amount of nitrate leaching through the vadose zone to the groundwater.

\section{Summary and conclusions}

Comparison of the groundwater pollution potential of greenhouses that grow year round vegetables under intensive regimes shows that commercial farms that rely on compost as the main fertilizer source, as commonly practiced in organic agriculture, result in substantial down-leaching of nitrate compared with farms that rely on fertigation methods, as commonly practiced in conventional agriculture.

The study implemented vadose zone monitoring technology that allowed frequent sampling of the sediment pore 
water at multiple points across the entire vadose cross section from the root zone to the water table over a long time period. Nitrate concentration profiles under the farms that rely on solid fertilizers revealed an increased concentration pattern with a depth to average of $724 \mathrm{mg} \mathrm{L}^{-1}$. On the other hand, concentration profiles in farms that rely on implementation of liquid fertilizers through the irrigation systems during the growing season exhibited a reducing concentration with a depth to average concentration of only $37.5 \mathrm{mg} \mathrm{L}^{-1}$, immediately under the root zone. Isotopic composition $\delta^{15} \mathrm{~N}$ and $\delta^{18} \mathrm{O}$ in nitrate from the vadose zone under the sites confirmed that the high nitrate concentration under the studied organic farms is likely to have originated from composted manure, while the nitrate under the studied conventional greenhouse, though in low concentrations, is likely to be from industrial or natural soil sources.

All studied greenhouses, organic and conventional, were established at the same time, grow similar vegetables, use similar amounts of water and total $\mathrm{N}$-fertilizers, and share most agro-technical practices. Nevertheless, the main difference between the greenhouses is related to the fertilization regime. While organic agriculture in greenhouses relies mostly on solid fertilizers such as compost that is mixed with the top soil prior to plantation, the conventional agriculture usually relies on fertigation methods where liquid fertilizer is implemented through the irrigation system during the growing season. As such, establishment irrigation in intensive organic farms, which is implemented in the early stages of the growing season, resulted in high down-leaching of nitrate that is produced in the wet top soil. This down-leaching is unavoidable since the soil is wet while plants roots are undeveloped and incapable of significant water and nutrient uptake. On the other hand, in typical conventional agriculture fertilizers are implemented along the growing season with the irrigation system according to the plant demand. As such nutrient uptake by the plant is more efficient, and down-leaching of nitrate is minimal. This concept has been approved on one of the organic farms that practice fertigation methods rather than application of solid compost in the soil. In this farm liquid fertilizers that were produced from guano extracts were implemented through the irrigation system. As a result, the vadose zone nitrate profile characteristics on this organic farm were similar to those observed in conventional farms and significantly lower than those observed in organic farms that rely on compost as the main fertilizer.

Long-term decision making on groundwater resource management requires substantial data on the fate of pollutant transport from their sources near land surface across the vadose zone to the groundwater. Data on the link between land use and groundwater quality may be obtained through monitoring technologies that are designed to provide real-time information on the quality of the percolating water across the vadose zone. In this study we have demonstrated how implementation of vadose zone monitoring systems provided valuable information on potential pollution threat to groundwater long before groundwater pollution became evident.

Acknowledgements. The authors wish to express their gratitude to the farmers who allowed us to conduct this study in their fields. We would like to thank Sara Elchanani and the Division of Water Quality of the Israel Water Authority for supporting and funding the project. The project was partly supported by the Koshland foundation.

Edited by: E. Zehe

\section{References}

Amiaz, Y., Sorek, S., Enzel, Y., and Dahan, O.: Solute transport in the vadose zone and groundwater during flash floods, Water Resour. Res., 47, W10513, doi:10.1029/2011WR010747, 2011.

APHA: Standard Methods for the Examination of Water and Wastewater, 17th Edn., American Public Health Association, Washington, D.C., 1989.

APHA: Standard Methods for the Examination of Water and Wastewater, 21st Edn., American Public Health Association, Washington, D.C., 2005.

Baram, S., Kurtzman, D., and Dahan, O.: Water percolation through a clayey vadose zone, J. Hydrol., 424, 165-171, 2012 a.

Baram, S., Arnon, S., Ronen, Z., Kurtzman, D., and Dahan, O.: Infiltration mechanism controls nitrification and denitrification processes under dairy waste lagoon, J. Environ. Qual., 41, 16231632, $2012 b$.

Ben-Gal, A., Ityel, E., Dudley, L., Cohen, S., Yermiyahu, U., Presnov, E., Zigmond, L., and Shani, U.: Effect of irrigation water salinity on transpiration and on leaching requirements: a case study for bell peppers, Agr. Water Manage., 95, 587-597, 2008.

Benton, J.: Soil Analysis Handbook of Reference Methods: Soil and Plant Analysis Counsil, Inc. CRC Press LLC, Boca Raton, FL, 1999.

Burow, K. R., Nolan, B. T., Rupert, M. G., and Dubrovsky, N. M.: Nitrate in groundwater of the United States, 1991-2003, Environ. Sci. Technol., 44, 4988-4997, 2010.

Dahan, O., Shani, Y., Enzel, Y., Yechieli, Y., and Yakirevich, A.: Direct measurements of floodwater infiltration into shallow alluvial aquifers, J. Hydrol., 344, 157-170, 2007.

Dahan, O., Tatarsky, B., Enzel, Y., Kulls, C., Seely, M., and Benito, G.: Dynamics of flood water infiltration and ground water recharge in hyperarid desert, Groundwater, 46, 450-461, 2008.

Dahan, O., Talby, R., Yechieli, Y., Adar, E., Lazarovitch, N., and Enzel, Y.: In situ monitoring of water percolation and solute transport using a vadose zone monitoring system, Vadose Zone J., 8, 916-925, 2009.

Dudley, L. M., Ben-Gal, A., and Lazarovitch, N.: Drainage water reuse: biological, physical, and technological considerations for system management, J. Environ. Qual., 37, 25-35, 2008.

EPA: http://www.epa.gov/oecaagct/torg.html, last access: 1 December 2013.

Feaga, J. B., Selker, J. S., Dick, R. P., and Hemphill, D. D.: Longterm nitrate leaching under vegetable production with cover crops in the Pacific Northwest, Soil Sci. Soc. Am. J., 74, 186$195,2010$. 
Harter, T., Davis, H., Mathews, M. C., and Meyer, R. D.: Shallow groundwater quality on dairy farms with irrigated forage crops, J. Contam. Hydrol., 55, 287-315, 2002.

Israel Meteorological Service: http://ims.gov.il, last access: 2 December 2013.

Israeli water authority: http://www.water.gov.il/Hebrew/ ProfessionalInfoAndData/Data-Hidrologeime/DocLib/

PerennialData-Coastal02.pdf, last access: 2 December 2013.

Jensen, M. M., Jorgensen, H., Halekoh, U., Watzl, B., ThorupKristensen, K., and Lauridsen, C.: Health biomarkers in a rat model after intake of organically grown carrots, J. Sci. Food Agr., 92, 2936-2943, 2012.

Kendall, C. and McDonnell, J. J.: Isotope Tracers in Catchment Hydrology, Elsevier, Amsterdam, the Netherlands, 1999.

Kourakos, G., Klein, F., Cortis, A., and Harter, T.: A groundwater nonpoint source pollution modeling framework to evaluate longterm dynamics of pollutant exceedance probabilities in wells and other discharge locations, Water Resour. Res., 48, W00L13, doi:10.1029/2011WR010813, 2012.

Kurtzman, D. and Scanlon, B. R.: Groundwater recharge through vertisols: irrigated cropland vs. natural land, Israel, Vadose Zone J., 10, 662-674, 2011.

Kurtzman, D., Shapira, R. H., Bar-Tal, A., Fine, P., and Russo, D.: Nitrate fluxes to groundwater under citrus orchards in a Mediterranean climate: observations, calibrated models, simulations and agro-hydrological conclusions. J. Contam. Hydrol., 151, 93-104, 2013

Liao, L., Green, C. T., Bekins, B. A., and Bohlke, J. K.: Factors controlling nitrate fluxes in groundwater in agricultural areas, Water Resour. Res., 48, W00L09, doi:10.1029/2011WR011008, 2012.

McIlvin, M. R. and Altabet, M. A.: Chemical conversion of nitrate and nitrite to nitrous oxide for nitrogen and oxygen isotopic analysis in freshwater and seawater, Anal. Chem., 77, 5589-5595, 2005.

Melo, A., Pinto, E., Aguiar, A., Mansilha, C., Pinho, O., and Ferreira, I.: Impact of intensive horticulture practices on groundwater content of nitrates, sodium, potassium, and pesticides, Environ. Monit. Assess., 184, 4539-4551, 2012.

Morari, F., Lugato, E., Polese, R., Berti, A., and Giardini, L.: Nitrate concentrations in groundwater under contrasting agricultural management practices in the low plains of Italy, Agr. Ecosys. Environ., 147, 47-56, 2012.

Oren, O., Yechieli, Y., Bohlke, J. K., and Dody, A.: Contamination of groundwater under cultivated fields in an arid environment, central Arava Valley, Israel, J. Hydrol., 290, 312-328, 2004.

Organic Centre Wales: http://www.organiccentrewales.org.uk/, last access: 1 December 2013.
Osenbruck, K., Fiedler, S., Knoller, K., Weise, S. M., Sultenfuss, J., Oster, H., and Pang, X. P., and Letey, J.: Organic farming: challenge of timing nitrogen availability to crop nitrogen requirements, Soil Sci. Soc. Am. J., 64, 247-253, 2000.

Rimon, Y., Dahan, O., Nativ, R., and Geyer, S.: Water percolation through the deep vadose zone and groundwater recharge: preliminary results based on a new vadose zone monitoring system, Water Resour. Res., 43, W05402, doi:10.1029/2006WR004855, 2007.

Rimon, Y., Nativ, R., and Dahan, O.: Physical and chemical evidence for pore-scale dual-domain flow in the vadose zone, Vadose Zone J., 10, 322-331, 2011 a.

Rimon, Y., Nativ, R., and Dahan, O.: Vadose zone water pressure variation during infiltration events, Vadose Zone J., 10, 1105$1112,2011 b$

Seufert, V., Ramankutty, N., and Foley, J. A.: Comparing the yields of organic and conventional agriculture, Nature, 485, 229-232, 2012.

Shani, U., Ben-Gal, A., Tripler, E., and Dudley, L. M.: Plant response to the soil environment: an analytical model integrating yield, water, soil type, and salinity, Water Resour. Res., 43, W08418, doi:10.1029/2006WR005313, 2007.

Strauch, G.: Timescales and development of groundwater pollution by nitrate in drinking water wells of the JahnaAue, Saxonia, Germany, Water Resour. Res., 42, W121416, doi:10.1029/2006WR004977, 2006.

Thompson, R. B., Martinez-Gaitan, C., Gallardo, M., Gimenez, C., and Fernandez, M. D.: Identification of irrigation and $\mathrm{N}$ management practices that contribute to nitrate leaching loss from an intensive vegetable production system by use of a comprehensive survey, Agr. Water Manage., 89, 261-274, 2007.

Trewavas, A.: Urban myths of organic farming, Nature, 410, 409_ 410, 2001.

Vazquez, N., Pardo, A., Suso, M. L., and Quemada, M.: Drainage and nitrate leaching under processing tomato growth with drip irrigation and plastic mulching, Agr. Ecosyst. Environ., 112, 313323, 2006.

Vitousek, P. M., Naylor, R., Crews, T., David, M. B., Drinkwater, L. E., Holland, E., Johnes, P. J., Katzenberger, J., Martinelli, L. A., Matson, P. A., Nziguheba, G., Ojima, D., Palm, C. A., Robertson, G. P., Sanchez, P. A., Townsend, A. R., and Zhang, F. S.: Nutrient imbalances in agricultural development, Science, 324 1519-1520, 2009.

Yin, F., Fu, B. J., and Mao, R. Z.: Effects of nitrogen fertilizer application rates on nitrate nitrogen distribution in saline soil in the Hai River Basin, China, J. Soil. Sediment., 7, 136-142, 2007. 